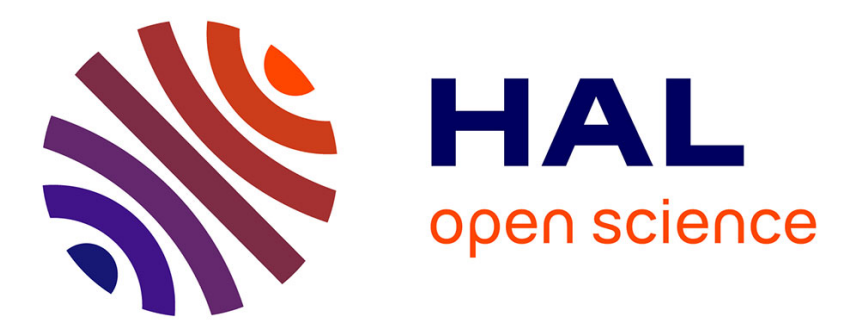

\title{
Identification of an eight-electron superatomic cluster and its alloy in one co-crystal structure
}

Jian-Hong Liao, Samia Kahlal, Yu-Chiao Liu, Ming-Hsi Chiang, Jean-Yves Saillard, C.W. Liu

\section{- To cite this version:}

Jian-Hong Liao, Samia Kahlal, Yu-Chiao Liu, Ming-Hsi Chiang, Jean-Yves Saillard, et al.. Identification of an eight-electron superatomic cluster and its alloy in one co-crystal structure. Journal of Cluster Science, 2018, 29 (5), pp.827-835. 10.1007/s10876-018-1353-y . hal-01874569

HAL Id: hal-01874569

https://hal-univ-rennes1.archives-ouvertes.fr/hal-01874569

Submitted on 14 Sep 2018

HAL is a multi-disciplinary open access archive for the deposit and dissemination of scientific research documents, whether they are published or not. The documents may come from teaching and research institutions in France or abroad, or from public or private research centers.
L'archive ouverte pluridisciplinaire HAL, est destinée au dépôt et à la diffusion de documents scientifiques de niveau recherche, publiés ou non, émanant des établissements d'enseignement et de recherche français ou étrangers, des laboratoires publics ou privés. 


\title{
Identification of an eight-electron superatomic cluster and its alloy in one co-crystal structure
}

Jian-Hong Liao, ${ }^{1}$ Samia Kahlal, ${ }^{2}$ Yu-Chiao Liu, ${ }^{3}$ Ming-Hsi Chiang, ${ }^{3}$ Jean-Yves Saillard, ${ }^{2, *}$ C. W. Liu ${ }^{1, *}$

${ }^{1}$ Department of Chemistry, National Dong Hwa University, Hualien 97401, Taiwan

(R.O.C.). E-mail: chenwei@mail.ndhu.edu.tw

${ }^{2}$ UMR-CNRS, 6226 “'Sciences Chimiques de Rennes”, Université de Rennes 1,

Rennes Cedex 35042, France

${ }^{3}$ Institute of Chemistry, Academia Sinica, Taipei 115, Taiwan (R.O.C.)

\begin{abstract}
Herein we report a crystal structure of $\left[\mathrm{Au}_{0.5} \mathrm{Ag}_{0.5} @ \mathrm{Ag}_{20}\left\{\mathrm{~S}_{2} \mathrm{P}\left(\mathrm{O}^{\mathrm{i}} \mathrm{Pr}\right)_{2}\right\}_{12}\right]\left(\mathrm{PF}_{6}\right)$ $\left[\mathrm{Cl} @ \mathrm{Ag}_{8}\left\{\mathrm{~S}_{2} \mathrm{P}\left(\mathrm{O}^{\mathrm{i}} \mathrm{Pr}\right)_{2}\right\}_{6}\right]\left(\mathrm{PF}_{6}\right)$ (1), which compositions were fully supported by positive-mode electrospray ionization mass spectroscopy. The structural elucidation indicates that the encapsulated atom of an $\mathrm{Ag}_{13}$ the entered icosahedron can be replaced by a gold atom. Surprisingly, the capping Ag atoms on the surface of an icosahedron in $\mathbf{1}$ reveal a different arrangement from the previously reported $\left[\mathrm{Ag}_{21}\left\{\mathrm{~S}_{2} \mathrm{P}\left(\mathrm{O}^{\mathrm{i}} \mathrm{Pr}\right)_{2}\right\}_{12}\right]\left(\mathrm{PF}_{6}\right)$ of $C_{3}$ symmetry. Besides, the preference for the central silver atom being oxidized by $\mathrm{Au}(\mathrm{I})$ is rationalized by the DFT calculations on three different computed $\left[\mathrm{AuAg}_{20}\left\{\mathrm{~S}_{2} \mathrm{PH}_{2}\right\}_{12}\right]^{+}$models having $C_{1}, C_{3}$, and $T$ symmetry, respectively.
\end{abstract}

Keywords silver $\bullet$ gold $\bullet$ alloys $\bullet$ superatoms $\bullet$ co-crystallization

\section{Introduction}

Atom-precise alloy nanoclusters (NCs) are emerging as a new class of materials in nanoscience because of their fascinating properties [1]. To date, a number of atomically precise gold [2] and silver [3] NCs have been identified by X-ray crystallography. Of late, researches on alloy NCs have gained momentum owing to witnessed unique advantages of alloys over the homo-metallic NCs ranging from enhanced stability, reactivity (including catalytic activity) and modulation of optical properties [4]. So far, a variety of atom-precise Au-based alloy NCs have been reported. Especially, the doping of $\mathrm{Au}_{25}(\mathrm{SR})_{18}$ clusters was extensively studied with metals such as $\mathrm{Cu}$ [5], Pd [6], Pt [6], Ag [5,7], Cd [8], and Hg [9] and the results imply 
that Pd, Pt, and Cd atoms preferentially occupy the inner icosahedral positions, Ag resides on the surface of the superatomic core whereas $\mathrm{Cu}$ and $\mathrm{Hg}$ are found in the staple motifs. On the other hand reports on silver alloy NCs are comparatively scarce.

Prominent silver/gold alloy examples being structurally characterized include $\mathrm{Au}_{25}$ ${ }_{x} \mathrm{Ag}_{\mathrm{x}}$ [10], $\mathrm{Au}_{38-\mathrm{x}} \mathrm{Ag}_{\mathrm{x}}$ [11], $\mathrm{Au}_{24} \mathrm{Ag}_{20}$ [12], $\mathrm{Au}_{24} \mathrm{Ag}_{46}$ [13], $\mathrm{Au}_{12} \mathrm{Ag}_{32}$ [3b], $\mathrm{Au}_{25} \mathrm{Ag}_{2}$ [14], $\mathrm{Ag}_{28} \mathrm{Au}$ [15], $\mathrm{Au}_{12} \mathrm{Ag}_{13}$ [16], $\mathrm{Au}_{80} \mathrm{Ag}_{30}$ [17], $\mathrm{Au}_{3} \mathrm{Ag}_{38}$ [18], $\mathrm{Au}_{7} \mathrm{Ag}_{8}$ [19], and $\mathrm{Au}_{\mathrm{x}} \mathrm{Ag}_{\mathrm{y}}$ [20] (clusters of clusters/supra clusters). Bakr et al. have successfully doped $\mathrm{Ag}_{25}(\mathrm{SR})_{18}$ with various metal atoms ( $\mathrm{Au}, \mathrm{Pd}, \mathrm{Pt}$ ). They also introduced controlled multimetallic doping in $\mathrm{Ag}_{25} \mathrm{NCs}$ [21]. Quite recently our group isolated the $\left[\mathrm{Au} @ \mathrm{Ag}_{20}\left\{\mathrm{Se}_{2} \mathrm{P}(\mathrm{OEt})_{2}\right\}_{12}\right]^{+}$alloy by doping an Au atom into $\left[\mathrm{Ag}_{21}\left\{\mathrm{Se} 2 \mathrm{P}(\mathrm{OEt})_{2}\right\}_{12}\right]^{+}$ via a galvanic replacement method [22]. Despite the tremendous progresses in their synthesis and characterization, the mechanistic studies for the formation of Ag alloy NCs are lagged significantly behind. So it thereof needs an effort to understand the fundamental underlying chemistry and certainly more mixed silver/gold nanoclusters with well defined structures are needed along this line.

\section{Experimental}

All the reactions were conducted under an $\mathrm{Ar} / \mathrm{N}_{2}$ atmosphere using standard Schlenk techniques. Solvents were distilled prior to use under nitrogen. All chemicals were purchased from commercial sources and were used as received. $\left[\mathrm{Ag}\left(\mathrm{CH}_{3} \mathrm{CN}\right)_{4}\right]\left(\mathrm{PF}_{6}\right)$ [23], and $\mathrm{NH}_{4}\left[\mathrm{~S}_{2} \mathrm{P}\left(\mathrm{O}^{\mathrm{i}} \mathrm{Pr}\right)_{2}\right.$ ] [24] were prepared as described in the literature. ESI-mass spectra were recorded on a Fison Quattro Bio-Q (Fisons Instruments, VG Biotech, $\mathrm{UK})$.

\section{Synthesis of $\left[\mathrm{AuAg}_{20}\left\{\mathrm{~S}_{2} \mathrm{P}\left(\mathrm{O}^{\mathrm{i}} \mathrm{Pr}\right)_{2}\right\}_{12}\right]\left(\mathrm{PF}_{6}\right)(1)$}

$\mathrm{Au}(\mathrm{THT}) \mathrm{Cl}$ (THT = tetrahydrothiophene) $(0.0867 \mathrm{~g}, 0.270 \mathrm{mmol})$ was added in a Schlenk tube, followed by cold DI water $(10 \mathrm{~mL})$ and $\mathrm{NaBH}_{4}(0.031 \mathrm{~g}, 0.811 \mathrm{mmol})$, then kept it stirring at room temperature under $\mathrm{N}_{2}$ gas. At the same time, in another Schlenk tube $\left[\mathrm{Ag}\left(\mathrm{CH}_{3} \mathrm{CN}\right)_{4}\right] \mathrm{PF}_{6}(0.113 \mathrm{~g}, 0.270 \mathrm{mmol}), \mathrm{NH}_{4}\left[\mathrm{~S}_{2} \mathrm{P}\left(\mathrm{O}{ }^{i} \mathrm{Pr}\right)_{2}\right]$ (0.050 g, $0.216 \mathrm{mmol}$ ) and THF (30 mL) were added, leading to become a colourless solution. After 10 minutes, the solution in the second Schlenk tube was transferred into the first one, then kept with stirring at room temperature for 6 hours. The reaction mixture was dried under vacuum to get dark red powder. $\mathrm{CH}_{2} \mathrm{Cl}_{2}$ was used for dissolving powder and passed through a short column packed with $\mathrm{Al}_{2} \mathrm{O}_{3}$. When a pink solution was separated, acetone was used to dissolve the residue on the column. A dark red solution was collected and concentrated to $\sim 10 \mathrm{~mL}$ under reduced pressure. Single crystals 
were grown by slow diffusion of $n$-hexane into the concentrated acetone solution. ESI-MS spectrum (m/z): [AuAg$\left.{ }_{20}\left\{\mathrm{~S}_{2} \mathrm{P}\left(\mathrm{O}^{\mathrm{i}} \mathrm{Pr}\right)_{2}\right\}_{12}\right]^{+}: 4913.2153$ (calc. 4913.2710), $\left[\mathrm{Ag}_{21}\left\{\mathrm{~S}_{2} \mathrm{P}\left(\mathrm{O}^{\mathrm{i}} \mathrm{Pr}\right)_{2}\right\}_{12}\right]^{+}: 4823.1943$ (calc. 4823.2095), $\left[\mathrm{Ag} 8(\mathrm{Cl})\left\{\mathrm{S}_{2} \mathrm{P}\left(\mathrm{O}^{\mathrm{i}} \mathrm{Pr}\right)_{2}\right\}_{6}\right]^{+}$: 2178.3167 (calc. 2178.3098).

\section{X-ray Crystallography}

Single crystals suitable for X-ray diffraction analysis of $\mathbf{1}$ were obtained by diffusing hexane into concentrated acetone solution at ambient temperature. The single crystal was mounted on the tip of glass fiber coated in paratone oil, then frozen at $150 \mathrm{~K}$. Data were collected on a Bruker APEX II CCD diffractometer using graphite monochromated Mo $\mathrm{K} \alpha$ radiation $(\lambda=0.71073 \AA)$. Absorption corrections for area detector were performed with SADABS [25] and the integration of raw data frame was performed with SAINT [26]. The structure was solved by direct methods and refined by least-squares against $F^{2}$ using the SHELXL-97 package [27], incorporated in SHELXTL/PC V6.14 [28]. All non-hydrogen atoms were refined anisotropically. Selected crystallographic data is listed in Table 1 . The central atomic site was initially refined with a fully occupied Au atom. It revealed a deep difference hole (-7.992 e/ $\left.\AA^{3}\right)$ around the central atom. This indicates that the actual electron density of the central atom is smaller than that of an Au atom. By comparison, a fully-occupied Ag atom was placed in the center instead of an Au atom. Although the R1 value slightly droped from $6.13 \%$ to $5.75 \%$, this time a high positive difference peak $\left(7.120 \mathrm{e} / \AA^{3}\right)$ appeared at central Ag atom. Then we realized that the electron density is intermediate between Ag and Au. Eventually, the central atomic site was refined with $50 \%$ of $\mathrm{Au}$ and $50 \%$ of Ag, and both atoms were constrained in the same position. As a result, $R 1$ $[\mathrm{I}>2 \sigma(\mathrm{I})]$ is $4.78 \%$ and $w R_{2}$ (all data) is $12.59 \%$ in the final refinement. The comparison of $\mathrm{R}$ values is based on the same GOF number. A side product, $\left[\mathrm{Ag}_{8}(\mathrm{Cl})\left\{\mathrm{S}_{2} \mathrm{P}\left(\mathrm{O}^{i} \mathrm{Pr}\right)_{2}\right\}_{6}\right]\left(\mathrm{PF}_{6}\right)$, and hexane molecules are found to co-crystallize. Thus, the crystal can be formulated as $\left\{\left[\mathrm{AuAg}_{20}\left\{\mathrm{~S}_{2} \mathrm{P}\left(\mathrm{O}^{i} \mathrm{Pr}\right)_{2}\right\}_{12}\right]\left(\mathrm{PF}_{6}\right)\right\}_{0.5}\left\{\left[\mathrm{Ag}_{21}\left\{\mathrm{~S}_{2} \mathrm{P}\left(\mathrm{O}^{i} \mathrm{Pr}\right)_{2}\right\}_{12}\right]\left(\mathrm{PF}_{6}\right)\right\}_{0.5} \cdot\left[\mathrm{Ag}_{8}(\mathrm{Cl})\left\{\mathrm{S}_{2} \mathrm{P}\left(\mathrm{O}^{i} \mathrm{Pr}\right)_{2}\right.\right.$ \}$\left._{6}\right]\left(\mathrm{PF}_{6}\right) \cdot(n$-hexane $)$.

Table 1. Selected crystallographic data for $\mathbf{1}$.

\begin{tabular}{ll}
\hline Empirical formula & $\mathrm{C}_{111} \mathrm{H}_{259} \mathrm{Ag}_{28.5} \mathrm{Au}_{0.5} \mathrm{ClF}_{12} \mathrm{O}_{36} \mathrm{P}_{20} \mathrm{~S}_{36}$ \\
Formula weight & 7379.96 \\
Crystal system, space group & Triclinic, $P(-) 1$ \\
a, $\AA$ & $19.7822(10)$ \\
b, $\AA$ & $20.9570(10)$
\end{tabular}




\begin{tabular}{|c|c|}
\hline c, $\AA$ & 28.8677(13) \\
\hline$\alpha$, deg. & $91.7072(16)$ \\
\hline$\beta$, deg & $95.0276(12)$ \\
\hline$\gamma, \operatorname{deg}$ & $92.1730(13)$ \\
\hline Volume, $\AA^{3}$ & 11906.6(10) \\
\hline $\mathrm{Z}$ & 2 \\
\hline$\rho_{\text {calcd }}, \mathrm{g} \cdot \mathrm{cm}^{-3}$ & 2.058 \\
\hline$\mu, \mathrm{mm}^{-1}$ & 3.110 \\
\hline Temperature, K & $150(2)$ \\
\hline$\theta_{\max }$, deg. / Completeness, \% & $25.0 / 99.8$ \\
\hline Reflections collected / unique & $102579 / 41834\left[\mathrm{R}_{\mathrm{int}}=0.0242\right]$ \\
\hline restraints / parameters & 3954 / 2624 \\
\hline$R 1^{\mathrm{a}}, w R 2^{\mathrm{b}}[\mathrm{I}>2 \sigma(\mathrm{I})]$ & $0.0482,0.1083$ \\
\hline$R 1^{\mathrm{a}}, w R 2^{\mathrm{b}}$ (all data) & $0.0600,0.1163$ \\
\hline Goodness of fit & 1.075 \\
\hline Largest diff. peak and hole, e/ $\AA^{3}$ & 2.017 and -2.266 \\
\hline
\end{tabular}

\section{Computational Details}

Geometry optimizations at the density functional theory (DFT) level were carried out using the Gaussian 09 package [29]. The BP86 [30] functional was used together with the general triple- $\xi$ polarized Def2-TZVPbasis set from EMSL basis set exchange library, with an all-electron basis set on silver. Vibrational frequency calculations were performed in order to assess energy minima. All the discussed relative energies $(\Delta \mathrm{E})$ are corrected from zero-point vibrational energy. Relative free energies $(\Delta G)$ refer to room temperature (298 K). Natural atomic orbital (NAO) populations were computed with the NBO 5.0 program [31].

\section{Results and Discussions}

In our search for alloy NCs passivated solely by dithiolate-type ligands, we have explored the reaction of gold salts in the presence of borohydrides with $\left[\mathrm{Ag}_{5}\left\{\mathrm{~S}_{2} \mathrm{P}\left(\mathrm{O}^{\mathrm{i}} \mathrm{Pr}\right)_{2}\right\}_{4}\left(\mathrm{PF}_{6}\right)\right]_{\mathrm{n}}$, a versatile precursor used in the build-up of various anion-encapsulated silver clusters [32]. Three cationic clusters were serendipitously isolated, co-crystallized with a solvated hexane molecule as hexafluorophosphate salts in a single compound $\mathbf{1}$ of composition $\left[\mathrm{Au}_{0.5} \mathrm{Ag}_{0.5} @ \mathrm{Ag}_{20}\left\{\mathrm{~S}_{2} \mathrm{P}\left(\mathrm{O}^{\mathrm{i}} \mathrm{Pr}\right)_{2}\right\}_{12}\right]\left[\mathrm{Cl} @ \mathrm{Ag}_{8}\left\{\mathrm{~S}_{2} \mathrm{P}\left(\mathrm{O}^{\mathrm{i}} \mathrm{Pr}\right)_{2}\right\}_{6}\right]\left(\mathrm{PF}_{6}\right)_{2}$. Among the three 
clusters present in 1, [Cl@Ag $\left.\left\{\mathrm{S}_{2} \mathrm{P}\left(\mathrm{O}^{\mathrm{i}} \mathrm{Pr}\right)_{2}\right\}_{6}\right]^{+}$exhibits a chloride-encapsulating cubic core of $\mathrm{Ag}(\mathrm{I})$ metals to which are bonded 6 dithiphosphate (dtc) ligands in a $\left(\mu_{2}, \mu_{2}\right)$ tetrametallic-tetraconnective pattern (Figure 1). Its idealized symmetry is $T_{h}$ and it is isostructural with a previously reported $\mathrm{X} @ \mathrm{Ag}_{8}$ species $(\mathrm{X}=\mathrm{F}, \mathrm{Br})$ [32c]. The $\mathrm{Ag}-\mu_{8} \mathrm{Cl}$ distances ranges from 2.837(2) to 2.874(2) $\AA$ and the Ag..Ag edge distances are in the range of 3.180(1) to 3.450(2) $\AA$ (avg. 3.300(1) $\AA$ ). They are comparable to those reported in [Cl@ $\left.\mathrm{Ag}_{8}\left\{\mathrm{Se} e_{2} \mathrm{P}(\mathrm{OEt})_{2}\right\}_{6}\right]^{+}$[33]. The formation of $\mathrm{Cl} @ \mathrm{Ag}_{8}$ can be attributed to the slow decomposition of both $\mathrm{Ag}_{21}$ and Au@Ag 20 in the crystallization. It is reasonable to propose that the chlorides are originating from the dichloromethane solvent and formed during the purification period. It is likely that the presence of $\mathrm{Cl@Ag}$ leads to a better molecular stacking with $\mathrm{Au@Ag} 20$ and $\mathrm{Ag}_{21}$. The two other clusters present in $\mathbf{1}$, are the isostructural $\left[\mathrm{M} @ \mathrm{Ag}_{20}\left\{\mathrm{~S}_{2} \mathrm{P}\left(\mathrm{O}^{\mathrm{i}} \mathrm{Pr}\right)_{2}\right\}_{12}\right]^{+}(\mathrm{M}=\mathrm{Ag}, \mathrm{Au})$ cations. Due to the similarity in the atomic radii $\left(1.44 \AA\right.$ ) of $\mathrm{Ag}$ and $\mathrm{Au}$, the central position inside their $\mathrm{Ag}_{20}$ skeleton contains, in the crystal, an Au/Ag atom, each in 50\% occupancy. This is reminiscent of the randomly distributed solid solution of the fcc bulk AgAu alloy. The refinement with partial Au occupancy was successful only at the central position whereas other metal positions are found to be of $100 \%$ Ag occupancy, further confirming that gold selectively occupies the central position. [AuAg$\left.{ }_{20}\left\{\mathrm{~S}_{2} \mathrm{P}\left(\mathrm{O}^{\mathrm{i}} \mathrm{Pr}\right)_{2}\right\}_{12}\right]^{+}$is composed of a central $\mathrm{Au}$ atom surrounded by $12 \mathrm{Ag}$ atoms, these 13 atoms constituting the inner icosahedral core (Figure 2a). The outer shell of the cluster is composed of 12

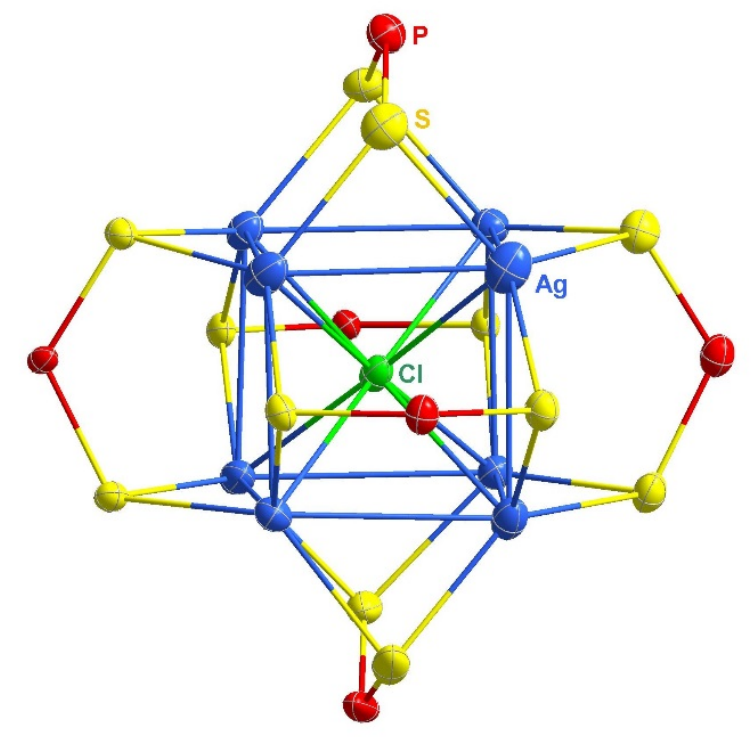

Figure 1. (a) A ORTEP drawing (30\% thermal ellipsoid) of $\left[\mathrm{Ag}_{8}\left\{\mathrm{~S}_{2} \mathrm{P}(\mathrm{O} \mathrm{Pr})_{2}\right\}_{6}\right]^{+}$ with isopropoxy groups omitted for clarity. Selected bond lengths $(\AA)$ and angles (deg.): Ag...Ag, 3.180(1)-3.450(2); Ag-Cl, 2.837(2)-2.874(2); S-Ag, 2.411(8)-2.617(4); S $\cdots$ S bite, 3.496(4)-3.53(1); Ag-S-Ag, 76.8(1)-86.09(8); S-P-S, 121.3(4)-122.1(1). 
dithiophosphate (dtp) ligands and 8 silver atoms which are capping 8 out of the 20 triangular faces of the $\mathrm{Ag}_{13}$ icosahedron (Figure 2b). The Ag-Ag distances in the centered icosahedral core lie in the range of 2.8487(8)-2.9909(8) $\AA$. They are close to that previously reported in ligated NCs having a similar centered icosahedral superatomic core: 2.8418(9)-3.0254(9) $\AA$ in $\mathrm{Ag}_{21}$ [3g], 2.8532(18)-3.0114(18) $\AA$ in $\mathrm{Ag}_{21}$ [22], and 2.8209-2.9975 $\AA$ in $\mathrm{Ag}_{25}$ [3d]. The Au-Agico distances are in the range of 2.7496(7)-2.8232(7) $\AA$ and close to those observed in Au@Ag (2.7589(11)-

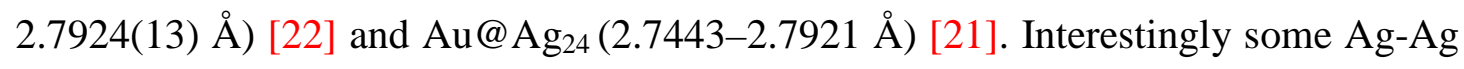
interactions, in the order of 3.210(2)-3.397(2) $\AA$, smaller than the sum of van der Waals radii for silver (3.40 $\AA$ ), are observed between the capping and the wingtip silver atoms of adjacent butterfly groups. Such a general feature of an $\mathrm{Ag}_{13}$ or $\mathrm{AuAg}_{12}$ centered icosahedron surrounded by an outer shell made of 8 supplementary silver atoms and $12 \mathrm{dtp}$ or didelenophosphate (dsep) ligands has been reported in our group and corresponds to a mixed-valent 8-electron $\left[\mathrm{M}_{13}\right]^{5+}$ superatomic core passivated by 8 formally cationic $\mathrm{Ag}(\mathrm{I})$ metals and 12 formally monoanionic ligands [3g, 3h, 22]. However, the actual $\left[\mathrm{MAg}_{20}\left\{\mathrm{~S}_{2} \mathrm{P}\left(\mathrm{O}^{\mathrm{i}} \mathrm{Pr}\right)_{2}\right\}_{12}\right]^{+}(\mathrm{M}=\mathrm{Ag}, \mathrm{Au})$ clusters, exhibit

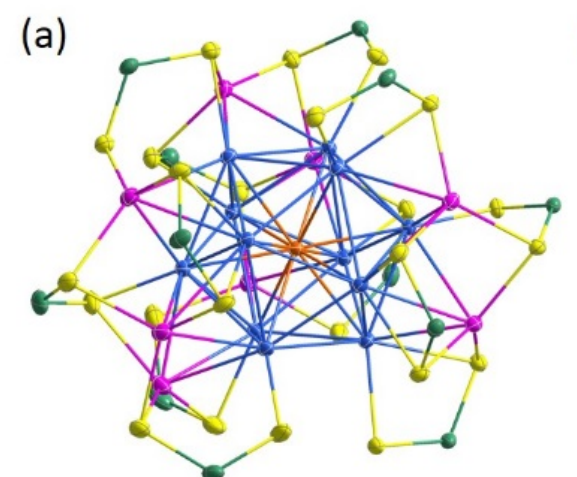

(c)

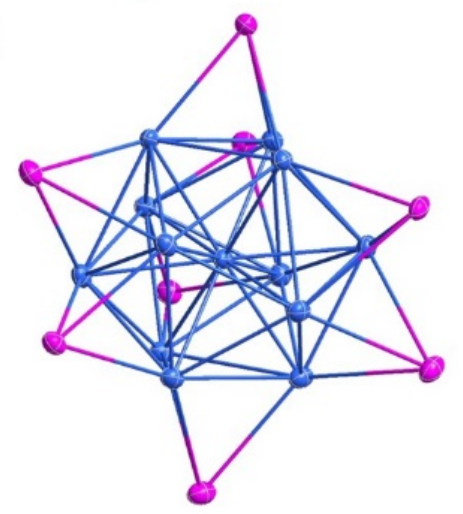

(b)

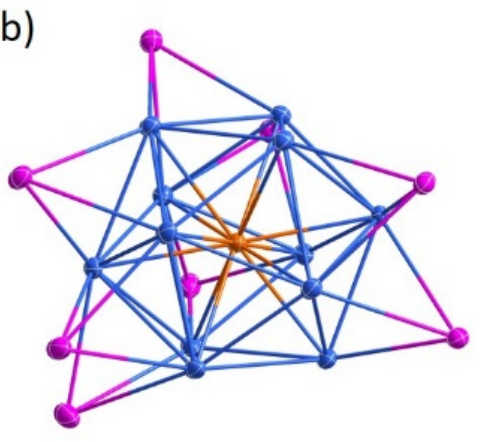

(d)

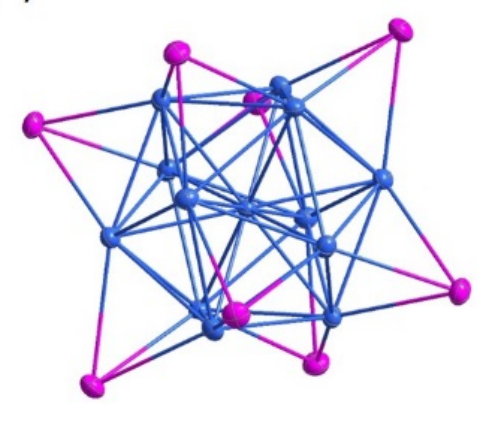

Figure 2. (a) A total structure of $\left[\mathrm{AuAg}_{20}\left\{\mathrm{~S}_{2} \mathrm{P}\left(\mathrm{O}^{\mathrm{i}} \mathrm{Pr}\right)_{2}\right\}_{12}\right]^{+}$with isopropoxy groups omitted for clarity. (b) The centered $\mathrm{Au@Ag} \mathrm{Ag}_{12}$ icosahedron with its 8 capping Ag atoms (violet). (c) The $\mathrm{Ag}_{21}$ core of $\left[\mathrm{Ag}_{21}\left\{\mathrm{~S}_{2} \mathrm{P}\left(\mathrm{O}^{\mathrm{i}} \mathrm{Pr}\right)_{2}\right\}_{12}\right]^{+}$in $C_{3}$ symmetry. (d) The $\mathrm{Ag}_{21}$ core of a predicted $T\left[\mathrm{Ag}_{21}\left\{\mathrm{~S}_{2} \mathrm{P}(\mathrm{OR})_{2}\right\}_{12}\right]^{+}$isomer [3g]. Color code: Au, orange; Ag blue (icosahedron) and violet (capping); S, yellow; P, green. 
significant structural differences with its relatives in the configuration of the passivating shell (capping Ag atoms and dtp ligands).

An approximate $C_{3}$ axis that passes through the center of two opposite triangular faces of the icosahedron can be seen in the previously reported Ag $_{21}$ cluster (Figure 2c). In contrast, the capping silver atom positions in the alloy NC are dramatically tilted, destroying completely the $C_{3}$ symmetry. The 12 dtp ligands exhibit five different types of coordination modes. Four of them bind to $2 \mathrm{Ag}_{\text {cap }}$ and $1 \mathrm{Ag}_{\text {ico }}$ in a trimetallic-triconnective coordination mode $\left(\eta^{3}: \mu_{2} ; \mu_{1}\right)$ : three ligands among them use the same sulfur atom to bind two $\mathrm{Ag}_{\text {cap }}$ atoms, and the fourth one uses two different sulfur atoms to bind two $\mathrm{Ag}_{\text {cap }}$ atoms. Another set of four dtp ligands coordinates to 2 $\mathrm{Ag}_{\text {cap }}$ and $1 \mathrm{Ag}_{\text {ico }}$ via a trimetallic-tetraconnective mode $\left(\eta^{3}: \mu_{2} ; \mu_{2}\right)$. A dimetallic-triconnective binding pattern to $1 \mathrm{Ag}_{\text {cap }}$ and $1 \mathrm{Ag}_{\text {ico }}\left(\eta^{2}: \mu_{2} ; \mu_{1}\right)$ is adopted by two other dtp ligands. Finally the last two ligands are connected to $3 \mathrm{Ag}_{\text {cap }}$ and 1 Agico through tetrametallic-tetraconnectivity $\left(\eta^{4}: \mu_{2} ; \mu_{2}\right)$. Very interestingly this bonding mode has not been observed previously in either $\mathrm{Ag}_{20}$ or $\mathrm{Ag}_{21}$ species.

The average bond lengths of $\mathrm{Ag}_{\text {ico }} \mathrm{S}$ and $\mathrm{Ag}_{\text {cap }} \mathrm{S}$ are $2.645 \AA$ and $2.524 \AA$ respectively, the average $S_{1} \cdots S_{2}$ bite distance is $3.412(3) \AA$. All these metric values are well matched with $2.670 \AA, 2.51 \AA$ and 3.401(5) $\AA$, respectively, observed in the $\mathrm{Ag}_{21} \mathrm{NC}$. Finally, it should be noted that the 8 capping silver atoms lie in a near planar $\mathrm{AgS}_{3}$ coordination environment, whereas the icosahedron silver atoms are in an $\mathrm{AgS}_{2}$ or AgS environment.

The composition of $\mathbf{1}$ is further proved by the positive ESI-MS (Figure 3), which displays peaks clearly corresponding to the intact molecular species of $\left[\mathrm{Au} @ \mathrm{Ag}_{20}\left\{\mathrm{~S}_{2} \mathrm{P}\left(\mathrm{O}^{\mathrm{i}} \mathrm{Pr}\right)_{2}\right\}_{12}\right]^{+},\left[\mathrm{Ag} @ \mathrm{Ag}_{20}\left\{\mathrm{~S}_{2} \mathrm{P}\left(\mathrm{O}^{\mathrm{i}} \mathrm{Pr}\right)_{2}\right\}_{12}\right]^{+}$, and $\left[\mathrm{Cl} @ \mathrm{Ag}_{8}\left\{\mathrm{~S}_{2} \mathrm{P}\left(\mathrm{O}{ }^{\mathrm{i}} \mathrm{Pr}\right)_{2}\right\}_{6}\right]^{+}$

(a)

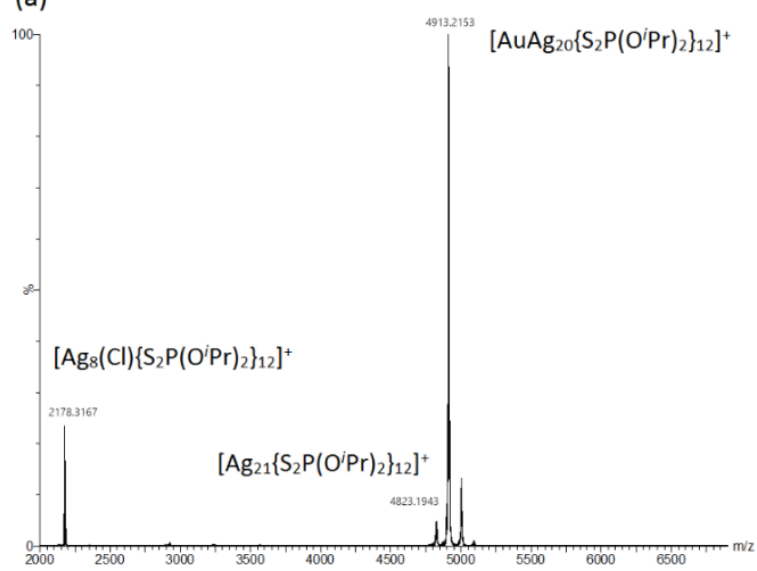

(b)

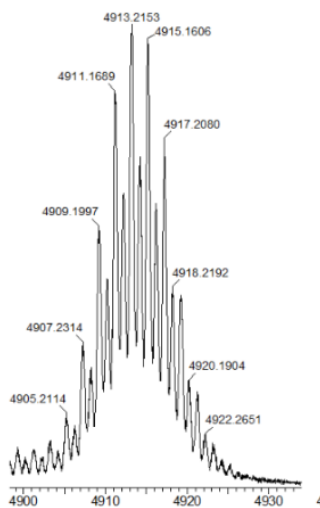

(c)

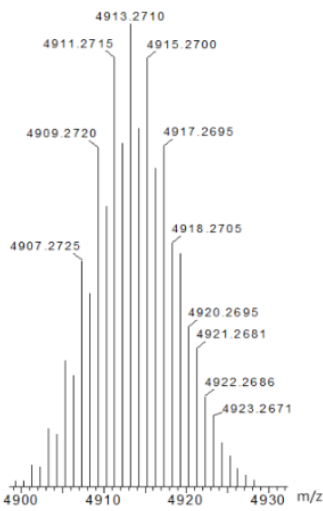

Figure 3. (a) Positive ESI-MS spectrum of compound 1. (b) Experimental and (c) simulated isotopic distribution patterns of $\mathrm{m} / \mathrm{z} 4913.22$, corresponding to the formula of $\left[\mathrm{AuAg}_{20}\left\{\mathrm{~S}_{2} \mathrm{P}\left(\mathrm{O}^{\mathrm{i}} \mathrm{Pr}\right)_{2}\right\}_{12}\right]^{+}$. 
at $\mathrm{m} / \mathrm{z} 4913.2153$ (calc. 4913.2710 ), 4823.1943 (calc. 4823.2095), and 2178.3167 (calc. 2178.3098), respectively. The formula assignments were further confirmed by their experimental isotopic distribution patterns that match closely with the simulated ones.

We attempted to develop a rational synthesis of the above described new

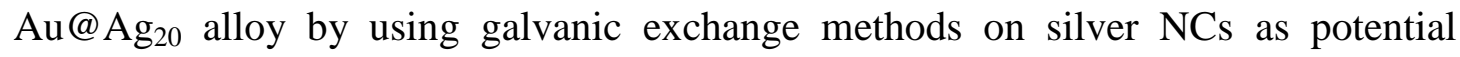
templates. Indeed, using dsep ligands, we have been recently sucessful in preparing two new 8-electron superatom type silver NCs, $\left[\mathrm{Ag}_{21}\left\{\mathrm{Se}_{2} \mathrm{P}(\mathrm{OEt})_{2}\right\}_{12}\right]^{+}$[22] and $\left[\mathrm{Au} @ \mathrm{Ag}_{20}\left\{\mathrm{Se}_{2} \mathrm{P}(\mathrm{OEt})_{2}\right\}_{12}\right]^{+}$[22]. The latter was formed via galvanic replacement reaction. We adopted a similar synthetic procedure by starting with [Ag@Ag $\left.\operatorname{Ag}_{20}\left\{\mathrm{~S}_{2} \mathrm{P}\left(\mathrm{O}^{\mathrm{i}} \mathrm{Pr}\right)_{2}\right\}_{12}\right]^{+}$, the central silver atom of which has a fairly negative charge (-0.86) [3g]. In a typical synthesis, $\left[\mathrm{Ag}_{21}\left\{\mathrm{~S}{ }_{2} \mathrm{P}\left(\mathrm{O}^{\mathrm{i}} \mathrm{Pr}\right)_{2}\right\}_{12}\right]\left(\mathrm{PF}_{6}\right)$ was firstly dissolved in tetrahydrofuran (THF), then $\mathrm{Au}\left(\mathrm{PPh}_{3}\right) \mathrm{Cl}$, was added instantaneously. The reaction was stirred at $-20^{\circ} \mathrm{C}$ for $2 \mathrm{~h}$. The solvents were removed under reduced pressure to obtain a dark red solid. The residue was thoroughly washed with a mixture of dichloromethane (DCM) and water mixture. The DCM layer was separated and dried under vacuum to yield the new Au@Ag 20 alloy NCs. Unfortunately single crystals produced by this galvanic replacement methods are so poor in quality that good diffraction data could not be collected. This is why we have undertaken the above-described alternative way, a co-reduction method, to synthesize the Au@Ag20 cluster from which single crystals of $\mathbf{1}$ with decent quality were obtained.

As said above, the common structural feature of the two clusters $\left[\mathrm{Au} @ \mathrm{Ag}_{20}\left\{\mathrm{~S}_{2} \mathrm{P}\left(\mathrm{O}^{\mathrm{i} P r}\right)_{2}\right\}_{12}\right]^{+}$and $\left[\mathrm{Ag} @ \mathrm{Ag}_{20}\left\{\mathrm{~S}_{2} \mathrm{P}\left(\mathrm{O}^{\mathrm{i}} \mathrm{Pr}\right)_{2}\right\}_{12}\right]^{+} \quad$ (of $C_{1}$ symmetry) reported here differs from the previously reported structure of $\left[\mathrm{Ag}_{21}\left\{\mathrm{~S}_{2} \mathrm{P}(\mathrm{O} \mathrm{Pr})_{2}\right\}_{12}\right]^{+}$ [3g], (of ideal $C_{3}$ symmetry) in the configuration of the superatom passivating shell (the 8 capping $\mathrm{Ag}^{+}$atoms and the $12 \mathrm{dtp}$ ligands). Thus, two isomers of $\left[\mathrm{Ag}_{21}\left\{\mathrm{~S}_{2} \mathrm{P}\left(\mathrm{O}^{\mathrm{i}} \mathrm{Pr}\right)_{2}\right\}_{12}\right]^{+}$are characterized at the solid state, so far. A third isomeric structure, (of $T$ symmetry) with another configuration of the passivating shell (Figure 2d), has been predicted by DFT calculations [3h] and recently characterized on the diselenophosphate analogue [22]. DFT calculations on the [Ag@ $\left.\mathrm{Ag}_{20}\left(\mathrm{~S}_{2} \mathrm{PH}_{2}\right)_{12}\right]^{+}$ model found that the relative free energies of the $C_{1}, C_{3}$ and $T$ isomers are 4.7, 0.0 and $2.3 \mathrm{kcal} / \mathrm{mol}$, respectively. The same calculations for the [Au@ $\left.\mathrm{Ag}_{20}\left(\mathrm{~S}_{2} \mathrm{PH}_{2}\right)_{12}\right]^{+}$model lead to the 4.9, 0.0 and $2.7 \mathrm{kcal} / \mathrm{mol}$ values, respectively (see Figure 4, first colum).. These quite small computed energy differences suggest that several isomers differing only from their outer shell configuration are likely to be observed, as already mentioned for the $\left[\mathrm{Ag}_{20}\left\{\mathrm{~S}_{2} \mathrm{P}(\mathrm{OR})_{2}\right\}_{12}\right]\left(\mathrm{R}=\mathrm{Pr},{ }^{\mathrm{i}} \mathrm{Pr}\right)$ series [3h].

The question of the location preference of $\mathrm{Au}$ in the $\mathrm{AuAg}_{20}$ alloy cluster can be first approached by considering the bare centered icosahedral $\left[\mathrm{AuAg}_{12}\right]^{5+}$ superatomic 
system, the $\left[\mathrm{Au} @ \mathrm{Ag}_{12}\right]^{5+}$ isomer of which being computed to be more stable than the [Ag@AuAg$\left.{ }_{11}\right]^{5+}$ one by $14.5 \mathrm{kcal} / \mathrm{mol}$ in free energy. Thus, in the isolated 8-electron superatomic core $\mathrm{Au}$ strongly prefers occupying the more electron-rich central position. In an $\left[\mathrm{AuAg}_{20}\left\{\mathrm{~S}_{2} \mathrm{P}\left(\mathrm{O}^{\mathrm{i}} \mathrm{Pr}\right)_{2}\right\}_{12}\right]^{+}$system, there are three chemically different classes of metal sites that gold can occupy: the center of the icosahedron, the icosahedral positions and that of the capping atoms which are in a formally $+\mathrm{I}$ oxidation state. In the $\mathrm{Ag}_{21} \mathrm{~T}$ structure described above, the 12 icosahedral atoms are all symmetry equivalent and the capping ones are split into two sets of 4 symmetry-equivalent atoms. The corresponding NBO (or NAO) charges computed for the $\left[\mathrm{Ag}_{21}\left(\mathrm{~S}_{2} \mathrm{PH}_{2}\right)_{12}\right]^{+} T$ model are $-0.45,+0.23,+0.60$ and +0.64 for the central, icosahedral and the two types of capping positions, respectively, suggesting that the central position is the most privileged for galvanic substitution. Indeed, when substituting one Ag atom by Au in any of these four symmetry (or different) positions, the most preferred substitution is again on the central atom, with relative free energies of 12.5, 20.8 and $22.5 \mathrm{kcal} / \mathrm{mol}$ for the icosahedral and the two capping positions, respectively (see Structures M7, M8 and M9 in last comumn of Figure 4).. A similar
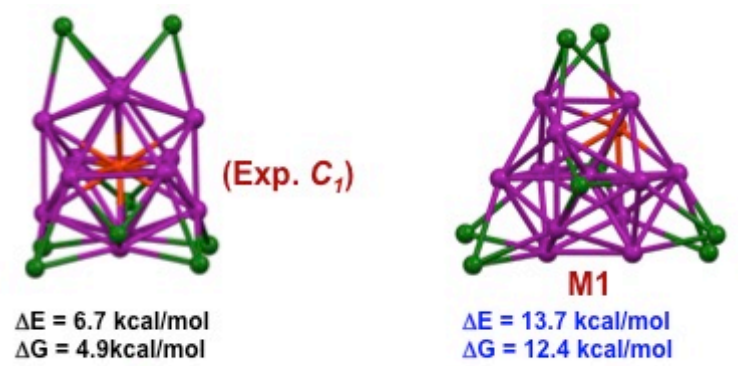

$\Delta \mathbf{G}=4.9 \mathrm{kcal} / \mathrm{mol}$

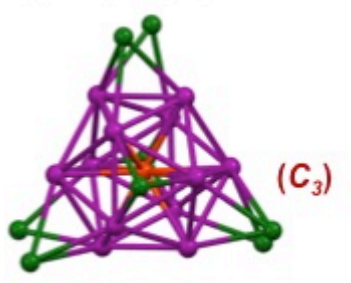

$\Delta \mathrm{E}=1.1 \mathrm{kcal} / \mathrm{mol}$ $\Delta \mathrm{G}=0.0 \mathrm{kcal} / \mathrm{mol}$

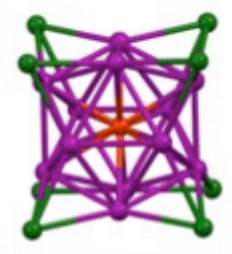

$\Delta \mathrm{E}=0.0 \mathrm{kcal} / \mathrm{mol}$ $\Delta \mathrm{G}=2.7 \mathrm{kcal} / \mathrm{mol}$

$(T)$

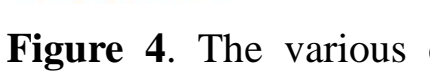

Figure 4. The various computed $\left[\mathrm{AuAg}_{20}\left\{\mathrm{~S}_{2} \mathrm{PH}_{2}\right\}_{12}\right]^{+}$models and their relative energies. First column: The Au@ $\mathrm{Ag}_{20}$ structures ( $C_{1}$ (this work), $C_{3}$ and $T$ (see text)). Middle, the Ag@AuAg 19 isomers derived from the $C_{3}$ structure (M1-M6). Last column, the Ag@AuAg 19 isomers derived from the $T$ structure (M7-M9). 
tendency was found for the $C_{3}$ structure where the central position was found to be preferred by $12.4-12.5 \mathrm{kcal} / \mathrm{mol}$ over the icosahedral positions and by $20-22 \mathrm{kcal} / \mathrm{mol}$ over the various capping positions (free energies; see Structures M1-M6 in the middle of Figure 4). Although the number of $\mathrm{Ag} @ \mathrm{AuAg}_{19}$ isomers in the title $C_{1}$ structure is too large for being calculated, it is clear that the same conclusion would be reached, i.e., the $\mathrm{M}^{\mathrm{I}}$ electron-poor capping positions are the least favored ones for gold substitution and the electron-rich central one is by far the most privileged.

\section{Conclusions}

In summary, a new alloy $\mathrm{NC}, \quad\left[\mathrm{AuAg}{ }_{20}\left\{\mathrm{~S}_{2} \mathrm{P}\left(\mathrm{O}^{\mathrm{i}} \mathrm{Pr}\right)_{2}\right\}_{12}\right]\left(\mathrm{PF}_{6}\right)$, was successfully synthesized and characterized by X-ray crystallography. The Au atom was found to be located at the center of an $\mathrm{Ag}_{12}$ icosahedron. [AuAg$\left.{ }_{20}\left\{\mathrm{~S}_{2} \mathrm{P}\left(\mathrm{O}^{\mathrm{i}} \mathrm{Pr}\right)_{2}\right\}_{12}\right]\left(\mathrm{PF}_{6}\right)$ co-crystallizes with $\left[\mathrm{Ag}_{21}\left\{\mathrm{~S}_{2} \mathrm{P}\left(\mathrm{O}^{\mathrm{i}} \mathrm{Pr}\right)_{2}\right\}_{12}\right]\left(\mathrm{PF}_{6}\right)$ and $\left[\mathrm{Ag}_{8}(\mathrm{Cl})\left\{\mathrm{S}_{2} \mathrm{P}\left(\mathrm{O}^{\mathrm{i}} \mathrm{Pr}\right)_{2}\right\}_{6}\right]\left(\mathrm{PF}_{6}\right)$ and their compositions were further confirmed by positive ESI mass spectroscopy. The capping Ag atoms on the icosahedral surface of $C_{1}$ symmetry in $\mathbf{1}$ are not arranged in a regular fashion as observed in the ordered structure of $C_{3}$ symmetry. The isomeric structures of both $\left[\mathrm{Ag} @ \mathrm{Ag}_{20}\left\{\mathrm{~S}_{2} \mathrm{P}\left(\mathrm{O}{ }^{\mathrm{i}} \mathrm{Pr}\right)_{2}\right\}_{12}\right]\left(\mathrm{PF}_{6}\right)$ clusters exhibit the same chemical composition but different arrangement of capping atoms. It is worthwhile to note that the modification of an icosahedral surface is quite unique in silver NCs with the protection of the bidentate dichalcogenolate ligand systems. This crystal structure indicates that a doping $\mathrm{Au}$ atom preferentially occupies the central position of the icosahedron. This is fully confirmed our DFT investigation which shows a large energy preference for this more electron-rich position, excluding the possibility of other positional isomers. These findings prompted us to explore the doping by various heteroatoms of noble-metal NCs (in particular $\mathrm{Ag}_{21}$ and $\mathrm{Ag}_{20}$ species). Such investigations are currently in progress.

\section{Electronic Supplementary Information (ESI)}

The structure reported herein has been deposited at the Cambridge Crystallographic Data Centre, CCDC 1523820 (1). For ESI and crystallographic data in CIF or other electronic format see doi:10.1039/x0xx00000x.

\section{Acknowledgement}

This work was supported by the Ministry of Science and Technology in Taiwan (MOST 106-2113-M-259-010-MY3). The GENCI-CINES and GENCI-IDRISS French national computer centers are acknowledged for computational resources (grant A0010807367). 


\section{References}

1. (a) R. Jin, C. Zeng, M. Zhou and Y. Chen (2016). Chem. Rev. 116, 10346. (b) R. R. Arvizo, S. Bhattacharyya, R. A. Kudgus, K. Giri, R. Bhattacharya and P. Mukherjee (2012). Chem. Soc. Rev. 41, 2943. (c) J. Sharma, R. Chhabra, A. Cheng, J. Brownell, Y. Liu and H. Yan (2009). Science 323, 112; (d) M. A. Noginov, G. Zhu, A. M. Belgrave, R. Bakker,V. M. Shalaev, E. E. Narimanov, S. Stout, E. Herz, T. Suteewong and U. Wiesner (2009). Nature 460, 1110.

2. (a) H. Qian, M. Zhu, Z.Wu, R. Jin, G. Li and R. Jin (2012). Acc. Chem. Res. 45, 1470. (b) J. F. Parker, C. A. Fields-Zinna and R. W. Murray (2010). Acc. Chem. Res. 43, 1289. (c) C. Zeng, H. Qian, T. Li, G. Li, N. L. Rosi, B. Yoon, R. N. Barnett, R. L. Whetten, U. Landman and R. Jin (2012). Angew. Chem. Int. Ed. 51, 13114. (d) C. Zeng, T. Li, A. Das, N. L. Rosi and R. Jin (2013). J. Am. Chem. Soc. 135, 10011. (e) X.-K. Wan, S.-F. Yuan, Z.-W. Lin and Q.-M. Wang (2014). Angew. Chem. Int. Ed. 53, 2923.

3. (a) A. Desireddy, B. C. Conn, J. Guo, B. Yoon, R. N. Barnett, B. N. Monahan, K. Kirschbaum, W. P. Griffith, R. L. Whetten, U. Andmann and T. P. Bigioni (2013). Nature 501, 399. (b) H. Yang, Y. Wang, H. Huang, L. Gell, L. Lehtovaara, S. Malola, H. Hakkinen and N. Zheng (2013). Nature Commun. 4, 2422. (c) D. Sun, G.-G. Luo, N. Zhang, R.-B. Huang and L.-S. Zheng (2011), Chem. Commun. 47, 1461. (d) C. P. Joshi, M. S. Bootharaju, M. J. Alhilaly and O. M. Bakr (2015). J. Am. Chem. Soc. 137, 11578. (e) L. G. AbdulHalim, M. S. Bootharaju, Q. Tang, S. d. Gobbo, R. G. AbdulHalim, M. Eddaoudi, D.-E. Jiang and O. M. Bakr (2015). J. Am. Chem. Soc. 137, 11970. (f) H. Yan, Y. Wang, X. Chen, X. Zhao, L. Gu, H. Huang, J. Yan, C. Xu, G. Li, J. Wu, A. J. Edwards, B. Dittrich, Z. Tang, D. Wang, L. Lehtovaara, H. Hakkinen and N. Zheng (2016). Nature Commun. 7, 12809. (g) R. S. Dhayal, J.-H. Liao, Y.-C. Liu, M.-H. Chiang, S. Kahlal, J.-Y. Saillard and C. W. Liu (2015). Angew. Chem. Int. Ed. 54, 3702. (h) R. S. Dhayal, Y.-R. Lin, J.-H. Liao, Y.-J. Chen, Y.-C. Liu, M.-H. Chiang, S. Kahlal, J.-Y. Saillard and C. W. Liu (2016). Chem. Eur. J. 22, 9943.

4. (a) H. Qian, D.-E. Jiang, G. Li, C. Gayathri, A. Das, R. R. Gil and R. Jin (2012). J. Am. Chem. Soc. 134, 16159. (b) S. Wang, X. Meng, A. Das, T. Li, Y. Song, T. Cao, X. Zhu, M. Zhu and R. Jin (2014). Angew. Chem. Int. Ed. 53, 2376. (c) Y. Negishi, T. Iwai and M. Ide (2010). Chem. Commun. 46, 4713. (d) Y. Negishi, W. Kurashige, Y. Niihori, T. Iwasa and K. Nobusada (2010). Phys. Chem. Chem. Phys. 12, 6219. (e) Y. Niihori, W. Kurashige, M. Matsuzaki and Y. Negishi (2013). Nanoscale 5, 508. 
5. S. Wang, Y. Song, S. Jin, X. Liu, J. Zhang, Y. Pei, X. Meng, M. Chen, P. Li and M. Zhu (2015). J. Am. Chem. Soc. 137, 4018.

6. R. Jin and K. Nobusada (2014). Nano Res. 7, 285.

7. Q. Li, S. Wang, K. Kirschbaum, K. J. Lambright, A. Das and R. Jin (2016). Chem. Commun. 52, 5194.

8. C. Yao, Y.-J. Lin, J. Yuan, L. Liao, M. Zhu, L.-H. Weng, J. Yang and Z. Wu (2015). J. Am. Chem. Soc. 137, 15350.

9. L. Liao, S. Zhou, Y. Dai, L. Liu, C. Yao, C. Fu, J. Yang and Z. Wu (2015). J. Am. Chem. Soc. 137, 9511.

10. Q. Li, S. Wang, K. Kirschbaum, K. J. Lambright, A. Dasa and R. Jin (2016). Chem. Commun. 52, 5194.

11. C. Kumara, K. J. Gagnon and A. Dass (2015). J. Phys. Chem. Lett. 6, 1223.

12. Y. Wang, H. Su, C. Xu, G. Li, L. Gell, S. Lin, Z. Tang, H. Häkkinen and N. Zheng (2015). J. Am. Chem. Soc. 137, 4324.

13. S. Wang, S. Jin, S. Yang, S. Chen, Y. Song, J. Zhang and M. Zhu (2015). Sci. Adv. 1, e1500441.

14. C. Yao, J. Chen, M. Li, L. Liu, J. Yang and Z. Wu (2015). Nano Lett. 15, 1281.

15. G. Soldan, M. A. Aljuhani, M. S. Bootharaju, L. G. AbdulHalim, M. R. Parida, A.-H. Emwas, O. F. Mohammed and O. M. Bakr (2016). Angew. Chem. Int. Ed. 55, 5749.

16. S. Wang, X. Meng, A. Das, T. Li, Y. Song, T. Cao, X. Zhu, M. Zhu and R. A. Zin (2014). Angew. Chem. Int. Ed. 53, 2376.

17. J.-L. Zeng, Z.-J. Guan, Y. Du, Z.-A. Nan, Y.-M. Lin and Q.-M. Wang (2016). J. Am. Chem. Soc. 138, 7848.

18. Z. Wang, R. Senanayake, C. M. Aikens, W.-M. Chen, C.-H. Tung and D. Sun (2016). Nanoscale 8, 18905.

19. Y. Wang, H. Su, L. Ren, S. Malola, S. Lin, B. K. Teo, H. Häkkinen and N. Zheng (2016). Angew. Chem. Int. Ed. 55, 15152.

20. B. K. Teo and H. Zhang (1991). Proc. Natl. Acad. Sci. 88, 5067.

21. (a) M. S. Bootharaju, C. P. Joshi, M. R. Parida, O. F. Mohammed and O. M. Bakr (2016). Angew. Chem. Int. Ed. 55, 922. (b) M. S. Bootharaju, L. Sinatra and O. M. Bakr (2016). Nanoscale 8, 17333.

22. W.-T. Chang, P.-Y. Lee, J.-H. Liao, K. K. Chakrahari, S. Kahlal, Y.-C. Liu, M.-H. Chiang, J.-Y. Saillard and C. W. Liu (2017). Angew. Chem. Int. Ed. 55, 14704.

23. A. A. M. Aly1, B. Walfortn and H. Lang (2014). Z. Kristallogr. NCS, 219, 489.

24. P. Wystrach, E. O. Hook and G. L. M. Christopher (1956). J. Org. Chem. 21, 705.

25. SADABS, version 2014-11.0, Bruker Area Detector Absorption Corrections (Bruker AXS Inc., Madison, WI, 2014). 
26. Included in G. Jogl, V4.043: Software for the CCD detector system (Bruker Analytical: Madison, WI, 1995).

27. (a) Sheldrick, G (2008). Acta Cryst. A 64, 112. (b) T. Gruene, H. W. Hahn, A. V. Luebben, F. Meilleur and G. M. Sheldrick (2014). J. Appl. Cryst. 47, 462.

28. SHELXTL, version 6.14. (Bruker AXS Inc., Madison, Wisconsin, USA, 2003).

29. Gaussian 09, Revision A.1, M. J. Frisch, G. W. Trucks, H. B. Schlegel, G. E. Scuseria, M. A. Robb, J. R. Cheeseman, G. Scalmani, V. Barone, B. Mennucci, G. A. Petersson, H. Nakatsuji, M. Caricato, X. Li, H. P. Hratchian, A. F. Izmaylov, J. Bloino, G. Zheng, J. L. Sonnenberg, M. Hada, M. Ehara, K. Toyota, R. Fukuda, J. Hasegawa, M. Ishida, T. Nakajima, Y. Honda, O. Kitao, H. Nakai, T. Vreven, J. A. Montgomery, Jr., J. E. Peralta, F. Ogliaro, M. Bearpark, J. J. Heyd, E. Brothers, K. N. Kudin, V. N. Staroverov, R. Kobayashi, J. Normand, K. Raghavachari, A. Rendell, J. C. Burant, S. S. Iyengar, J. Tomasi, M. Cossi, N. Rega, J. M. Millam, M. Klene, J. E. Knox, J. B. Cross, V. Bakken, C. Adamo, J. Jaramillo, R. Gomperts, R. E. Stratmann, O. Yazyev, A. J. Austin, R. Cammi, C. Pomelli, J. W. Ochterski, R. L. Martin, K. Morokuma, V. G. Zakrzewski, G. A. Voth, P. Salvador, J. J. Dannenberg, S. Dapprich, A. D. Daniels, Ö. Farkas, J. B. Foresman, J. V. Ortiz, J. Cioslowski, and D. J. Fox (Gaussian, Inc., Wallingford CT, 2009M).

30. (a) A. D. Becke (1988). Phys. Rev. A 38, 3098. (b) J. P. Perdew (1986). Phys. Rev. B 33, 8822.

31. E. D. Glendening, J. K. Badenhoop, A. E. Reed, J. E. Carpenter, J. A. Bohmann, C. M. Morales and F. Weinhold, NBO 5.0; Theoretical Chemistry Institute, University of Wisconsin (Madison, WI, 2001, http://www.chem.wisc.edu/ nbo5).

32. (a) C. W. Liu, H.-W. Chang, C.-S. Fang, B. Sarkar, J.-C. Wang (2010). Chem. Commun. 46, 4571. (b) J.-H. Liao, H.-W. Chang, H.-C. You, C.-S. Fang and C. W. Liu (2011). Inorg. Chem. 50, 2070. (c) J.-H. Liao, H.-W. Chang, Y.-J. Li, C.-S. Fang, B. Sarkar, W. E. van Zyl and C. W. Liu (2014). Dalton Trans. 43, 12380. (d) H.-W. Chang, J.-H. Liao, B. Li, Y.-J. Chen and C. W. Liu (2014). J. Struct. Chem. 55, 1426. (e) H.-W. Chang, R.-Y. Shiu, C.-S. Fang, J.-H. Liao, P. V. V. N. Kishore, S. Kahlal, J.-Y. Saillard and C. W. Liu (2017). J. Clust. Sci. 28, 679.

33. (a) C. W. Liu, H.-C. Haia, C.-M. Hung, B. K. Santra, B.-J. Liaw, Z. Lin, J.-C. Wang (2004). Inorg. Chem. 43, 4464. (b) C. W. Liu, C.-M. Hung, H.-C. Haia, B.-J. Liaw, L.-S. Liou, Y.-F. Tsai, J.-C. Wang (2003). Chem. Commun. 976. 